Criar Educação, Criciúma, v. 10, ํำ, jan/jul 2021.- PPGE - UNESC - ISSN 2317-2452

\title{
RELATO DE ENSINO EM MATEMÁTICA COM BASE NA TEORIA HISTÓRICO- CULTURAL: CONCEITO DE POLÍGONOS E FORMAS CIRCULARES
}

\author{
Lucas Vieira Machado ${ }^{1}$ \\ Alexandre Marcineiro Figueredo ${ }^{2}$ \\ Amanda de $\mathrm{Nez}^{3}$ \\ Eloir Fátima Mondardo Cardoso ${ }^{4}$
}

\begin{abstract}
RESUMO
O presente relato tem como objetivo a elaboração de uma proposta de ensino de matemática com base nos pressupostos da teoria Histórico-Cultural sobre geometria e a aplicação em duas turmas do sexto ano do ensino fundamental, nos municípios de Criciúma e Urussanga, Santa Catarina. A escolha deste tema, deu-se pelo fato de que a organização do ensino de geometria nos livros didáticos, de modo geral, se apresenta de forma isolada. Foi possível perceber que o professor ao utilizar a THC, proporciona ao aluno desenvolver o pensamento teórico, mas para que isso aconteça, o processo tem que ser mediado por tarefas que instiguem o discente a desenvolver seu raciocínio teórico nas relações em que envolviam geometria.
\end{abstract}

Palavras-Chave: Ensino; Geometria; Teoria Histórico-Cultural.

\section{MATH TEACHING REPORT BASED ON HISTORICAL-CULTURAL THEORY: CONCEPT OF POLYGONS AND CIRCULAR FORMS}

\begin{abstract}
This report aims to develop a proposal for teaching mathematics based on the assumptions of HistoricalCultural theory about geometry and the application in two classes of the sixth year of elementary school, in the municipalities of Criciúma and Urussanga, Santa Catarina. The choice of this theme was due to the fact that the organization of the teaching of geometry in textbooks, in general, presents itself in an isolated way. It was possible to perceive that the teacher, when using THC, allows the student to develop theoretical thinking, but for that to happen, the process has to be mediated by tasks that instigate the student to develop his theoretical reasoning in the relationships in which geometry was involved.
\end{abstract}

Keywords: Teaching; Geometry; Historical-Cultural Theory.

\footnotetext{
${ }^{1}$ Graduado em Licenciatura em Matemática pela Universidade do Extremo Sul Catarinense. Acadêmico de Psicologia da Universidade do Extremo Sul Catarinense. Email: lucasvieirapsi@ gmail.com

${ }^{2}$ Mestrando em Educação, Universidade do Extremo Sul Catarinense. Graduado em Licenciatura em

Matemática pela Universidade do Extremo Sul Catarinense. Email: alexandre_marfig@hotmail.com

3 Graduada em licenciatura em matemática pela Universidade do Extremo Sul Catarinense. Email: amandadenez1@gmail.com

${ }^{4}$ Professora de Estágio Supervisionado do Ensino Fundamental I e II do Curso de Matemática da UNESC. Coordenadora Pedagógica do Colégio de Aplicação da UNESC. Membro do grupo de estudos e pesquisa em Educação Matemática numa histórico-cultural abordagem (GPEMAHC) Formação: Graduada em Matemática, pós-graduação lato-sensu em Educação Matemática e strito-senso em Educação. Email: efm@unesc.net
} 


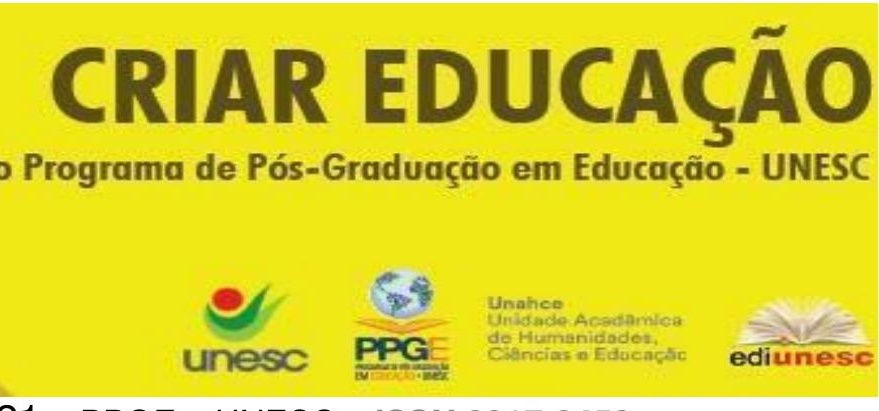

Criar Educação, Criciúma, v. 10, nº1, jan/jul 2021.- PPGE - UNESC - ISSN 2317-2452

\section{INTRODUÇÃO}

O presente artigo apresenta os resultados de uma intervenção didática acerca dos conceitos de polígonos e formas circulares, com a organização de ensino proposto por Davýdov e colaboradores, baseando-se nos pressupostos da teoria Histórico-Cultural. Nessa perspectiva, estudou-se a Proposta Curricular de Santa Catarina e de Criciúma concomitante à Teoria Histórico-Cultural (THC), no qual foi desenvolvido um plano de ensino que contemplasse o desenvolvimento do pensamento teórico do aluno, colocando-o em ação investigativa. Este trabalho foi desenvolvido nas disciplinas de Estágio Supervisionado do Ensino Fundamental I e II, pelo curso de Licenciatura em Matemática da Universidade do Extremo Sul Catarinense (UNESC).

Entende-se a importância deste trabalho, visto que, de maneira geral, a organização do ensino de geometria nos livros didáticos se apresenta de forma isolada. No entanto, de acordo com a THC, o ensino de matemática deve inter-relacionar as ideias geométricas, algébricas e aritméticas. Antes de iniciar os estudos e a elaboração do plano de ensino, foram contatadas duas escolas, uma situada no município de Criciúma - SC e a outra em Urussanga - SC, com a finalidade de desenvolver o estudo de polígonos e formas circulares, com estudantes do sexto ano do Ensino Fundamental. Na sequência foi conversado com duas professoras do sexto ano que lecionavam a disciplina de matemática, solicitando a autorização para desenvolver o estágio e, qual conteúdo poderia ser abordado. Após ficar decidido que poderíamos discutir a respeito de geometria plana, foi dado continuidade aos estudos.

Sendo assim, o objetivo foi a elaboração de uma proposta de ensino de matemática com base nos pressupostos da Teoria Histórico-Cultural sobre geometria e a aplicação em duas turmas do sexto ano do ensino fundamental, nos municípios de Criciúma e Urussanga, Santa Catarina.

\section{FUNDAMENTAÇÃO TEÓRICA}

Para que o homem se constitua como ser humano e em constante desenvolvimento, apenas o conhecimento empírico não é suficiente, isso se consolida pelo saber sistematizado. Para apropriação desse saber, as instituições de ensino desempenham importante papel, pois, é 


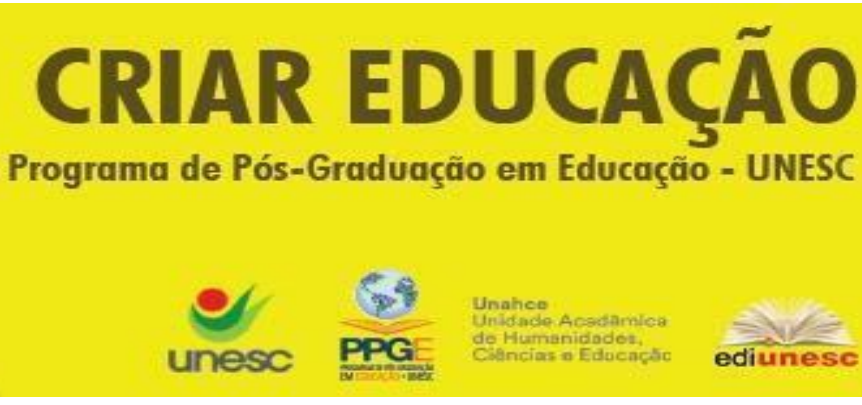

Criar Educação, Criciúma, v. 10, no1, jan/jul 2021.- PPGE - UNESC - ISSN 2317-2452

na escola que ocorre a "transmissão-assimilação" dos conhecimentos historicamente produzidos (SAVIANI, 2008). Moraes e Moura (2009, p. 99), corroboram com esse pensamento ao afirmar que a escola "é considerada o espaço por excelência dos conceitos científicos, a instituição capaz de fazer a mediação entre os conceitos cotidianos e o científico".

No entanto, de acordo com Libâneo (2004), as instituições de ensino têm se orientado, na sua maioria, pelos objetivos da pedagogia tradicional. Essa pedagogia de acordo com Davídov (1988), pressupõe a contemplação imediata dos dados sensoriais da realidade, que por sua vez, permite classificar e descrever o objeto tal como se apresenta na sua aparência externa, características do ensino para o desenvolvimento do pensamento empírico.

Para Davýdov (1998), o objetivo da educação escolar nos dias atuais não é apenas transmitir mecanicamente os conhecimentos, e sim ajudar os estudantes a encontrar seu próprio caminho para o desenvolvimento do pensamento teórico. Para isso, o ensino eficaz é aquele orientado pelos conceitos científicos e que condizem com o que de mais atual a humanidade produziu. Rosa (2012) salienta que, ao entrar na escola, a criança deve se sentir em um ambiente novo, caracterizado pelo teor científico dos conceitos. Segundo Davýdov, nas palavras de Damazio, Rosa e Euzébio (2012, p. 210) “o conteúdo e o método de ensino têm importância fundamental, por determinar o tipo de pensamento que se desenvolve nas crianças, durante a assimilação dos conhecimentos". Sendo assim, o pensamento teórico consiste na análise do objeto tomado em seu processo de desenvolvimento, de modo que reflita os nexos essenciais que se encontram intrínsecos no processo de sua formação.

Segundo Freire (2011, p. 117), “ensinar não é transmitir a inteligência do objeto ao educando, mas instigá-los", e para isso, o professor necessita de uma formação de qualidade que possibilite tais conhecimentos. Ele precisa desenvolver sua capacidade epistemológica, para que entenda a natureza do conhecimento, concepção e organização de ensino. E assim, consiga desenvolver de maneira didática seu ensino e transmitir seu conhecimento aos alunos.

Para a formação de indivíduos criticamente ativos é necessário que, desde o início da sua educação escolar, sejam encorajados à busca por conceitos próprios. Nesse sentido, o professor deve direcionar o aluno, mas não propiciar soluções previamente concluídas. Ao preparar sua aula, deve levar em consideração o diversificado desenvolvimento de seus alunos. 


\section{CRIAR EDUCAÇÃO}

Revista do Programa de Pós-Graduação em Educação - UNESC

Criar Educação, Criciúma, v. 10, no1, jan/jul 2021.- PPGE - UNESC - ISSN 2317-2452

Segundo Zanella (1994), a criança apresenta diferentes níveis de desenvolvimento: seja o real, em que consegue resolver de forma individual a lição; e o potencial, que advém das atividades que não desenvolve sozinho, apenas com o auxílio de alguém provecto no assunto. Diante disto, a Zona de Desenvolvimento Proximal consiste na distância entre o que se consegue fazer sozinho e o que precisa de auxílio de alguém mais experiente. No processo de desenvolvimento, a criança que está na zona de desenvolvimento real, utiliza-se da imitação para atingir a zona de desenvolvimento potencial (ZANELLA, 1994). Entretanto, ela permanece com características do sujeito ativo, pois interfere na apresentação dos conteúdos, não aceitando de forma passiva o que é ensinado. Neste momento, ela se encontra na zona de desenvolvimento proximal.

A criança, no processo de aprendizagem, utiliza vários meios para apropriação de conhecimentos, sendo um desses, a comparação. Portanto, é necessário o uso de objetos diversos e variados ou de um conjunto de impressões concretas para a comparação. Seu objetivo é fazer com que a criança amplie a capacidade de abstrair conhecimentos, e assim, chegar à generalização (SFORNI, 2003).

Apenas o pensamento empírico não soluciona os problemas apresentados nos ensinamentos escolares, são necessários conceitos científicos, pois estes desenvolvem o pensamento teórico, contribuindo para alcançar o resultado esperado. Segundo Peres e Freitas (2014, p. 20-21), “o ensino focado na formação de conceitos é, portanto, a forma de ensino pela qual os alunos conseguem compreender a origem dos objetos de conhecimento que estão aprendendo em uma matéria escolar".

Segundo Moretti (2014) para compreender o conceito é preciso assimilar o contexto gerador com a sua estrutura lógica formal. No processo de ensino-aprendizagem, para uma melhor compreensão dos conhecimentos, os exercícios devem estar associados ao tema trabalhado. De acordo com Moraes e Moura (2009, p. 105), "as atividades de ensino elaboradas pelos professores devem oferecer condições para que os escolares entendam a situação de aprendizagem e realizem ações com o objetivo de aprender". Sendo assim, evidencia-se a necessidade de as atividades estarem estruturadas de maneira correta e que tenham um objetivo bem definido. 


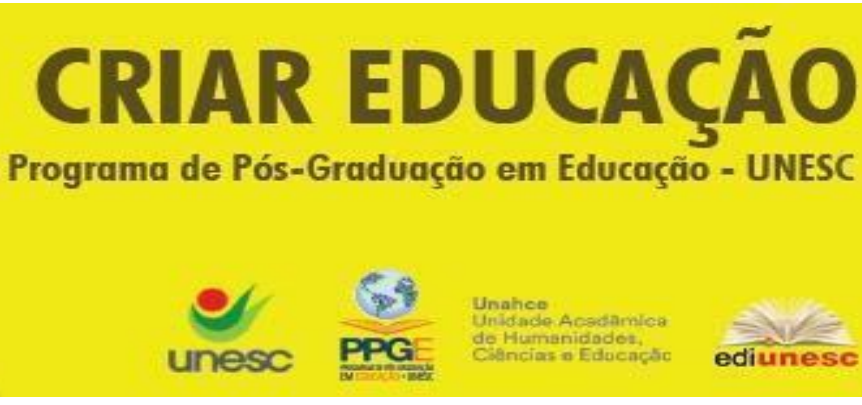

Criar Educação, Criciúma, v. 10, nำ1, jan/jul 2021.- PPGE - UNESC - ISSN 2317-2452

No desenvolvimento da ação pedagógica, se o conceito não estiver bem sistematizado, o aluno encontrará dificuldades, pois ele "fixa sua atenção nos traços secundários e não nos substanciais" (SFORNI, 2003, p. 141). Conforme o aluno avança na vida escolar, os conteúdos tornam-se mais complexos, exigindo maior abstração, entretanto, em muitos casos, ele não está preparado para tamanha concepção, com isso, amplia os obstáculos epistemológicos.

Segundo Moraes e Moura (2009, p. 101), para que aconteça um bom desenvolvimento no processo de aprendizagem, é necessário estimular o sujeito no crescimento educativo.

\section{METODOLOGIA}

A presente pesquisa é de cunho qualitativo, na qual, inicialmente, realizou-se uma pesquisa bibliográfica com estudos de textos que abordavam os pressupostos da THC, como também, a Proposta Curricular de Santa Catarina.

Após o estudo da THC e dos conceitos matemáticos, elaborou-se a proposta de ensino. Buscou-se elaborar nas tarefas de ensino, os estudos de Mame (2014) e Rosa (2012), visto que suas pesquisas se centram nos conceitos de geometria.

A prática docente foi realizada em duas escolas municipais, uma em Criciúma e a outra em Urussanga, ambas em Santa Catarina. Os conceitos foram desenvolvidos com duas turmas de sexto ano, ao todo, 47 estudantes participaram do estudo.

Durante o desenvolvimento do plano de ensino, foram feitas observações nas turmas para ter conhecimento dos mesmos e a partir do que foi visto, formular o plano de ensino. Após concluídas as observações e com o plano de ensino preparado, foi iniciado as aulas. As aulas eram ministradas pelos estagiários, mas a professora titular acompanhava e auxiliava quando necessário. No processo avaliativo, foram elaboradas três avaliações: a primeira individual e com consulta, a segunda em dupla e sem consulta, e a terceira individual. Esse método avaliativo foi desenvolvido com base no regulamento das escolas, que solicitaram no mínimo três avaliações.

\section{Concepção dos conceitos de geometria plana na teoria histórico-cultural}

Buscou-se organizar uma proposição de ensino com fundamentos na THC, para levar o aluno à apropriação dos conteúdos de geometria: ponto, retas, segmentos de retas, ângulos, polígonos e formas circulares. Para Mame (2014), faz-se necessária a relação entre abstrato e 
Criar Educação, Criciúma, v. 10, no1, jan/jul 2021.- PPGE - UNESC - ISSN 2317-2452

concreto do pensamento, entre a palavra e a imagem para a formação dos conceitos e a compreensão dos conteúdos ensinados. Diante disso, o professor dispõe do material visual nas suas aulas, para melhor entendimento dos conceitos. No entanto, não é aconselhável o uso exagerado de muitos objetos, é fundamental dar ênfase as características fundamentais do conceito no processo de apropriação (MAME, 2014). Ou seja, os objetos visuais desenvolvem papel secundário, não sendo eles o foco das tarefas e sim o conceito.

Segundo Rosa (2012, p. 71),

Davydov considera que a base de todo o conhecimento humano é a prática-objetal. Desse modo, os objetos e figuras são os instrumentos que orientam as crianças na realização do sistema de tarefas que promovem o desenvolvimento da ação investigativa, sob a direção do professor.

Portanto, a primeira tarefa proposta relaciona forma e cor. Apresentando ao aluno um conjunto de folhas com aspectos variados, o aluno deveria agrupar as imagens com características semelhantes (Figura 1). Segundo Mame (2014), é necessário discutir com o discente as diversas possibilidades de respostas, levando-o a pensar sobre os agrupamentos que não estão de acordo. Embora as folhas não possuam as formas geométricas bidimensionais, que geralmente são conceitos estudados nas escolas, pode ser que elas apresentem aspectos historicamente produzidos no desenvolvimento da geometria (MAME, 2014). Ou seja, por vezes é possível identificar formas irregulares que lembram uma figura dimensional estudada.

Figura 1 - Tarefa 1: Classificação de folhas

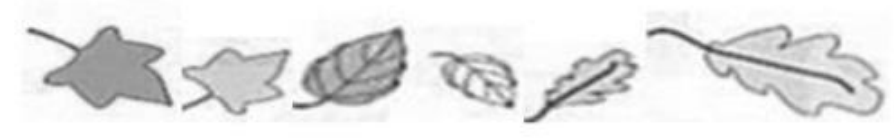

Fonte: Mame (2014, p. 58).

Com o auxílio de uma tesoura, eles recortaram a imagem das folhas, agruparam as folhas semelhantes e na sequência, colaram no caderno. Após concluírem essa tarefa, foram questionados: Por que vocês agruparam desta maneira? Alguns responderam: As imagens têm formas semelhantes, o que mudam são seus tamanhos e suas cores (Figura 2).

Figura 2 - Tarefa 1: Desenvolvimento do estudante 


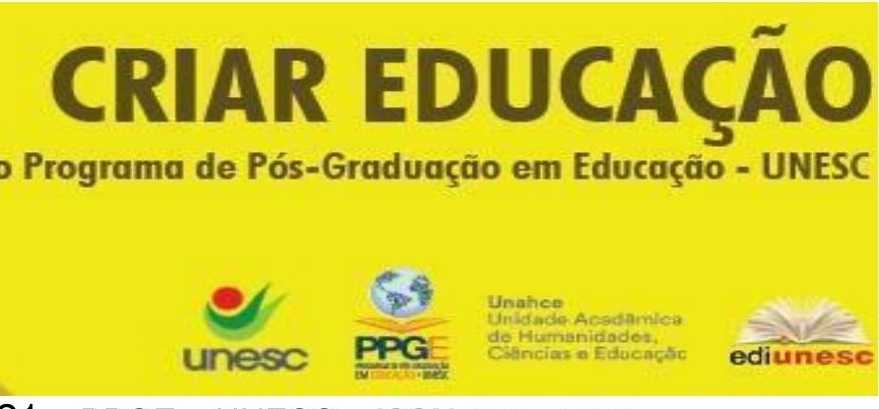

Criar Educação, Criciúma, v. 10, no1, jan/jul 2021.- PPGE - UNESC - ISSN 2317-2452

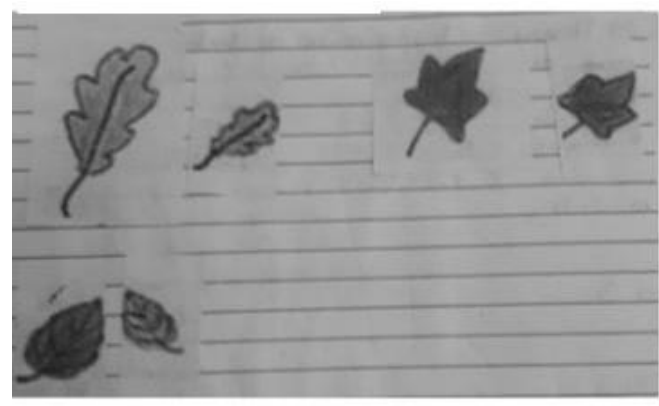

Fonte: Caderno do estudante.

Na segunda tarefa, o professor mostrou outras figuras, agora com formatos diferentes e mesma cor (Figura 3). Neste momento, as imagens utilizadas não provêm da natureza, e sim da produção humana (MAME, 2014). Foi proposto que adivinhassem, entre as figuras apresentadas, aquela escolhida por ele (professor). Durante esse processo, é aconselhável ao docente estimular os alunos a fazerem questionamentos. "Nessa situação, é possível a ocorrência de até quatro perguntas, pois têm à disposição cinco possibilidades”, entretanto, o objetivo é que se faça o mínimo de perguntas possíveis (ROSA, 2012, p. 73). Espera-se que expressem a seguinte indagação: Que forma tem a figura que você pensou? (MAME, 2014).

Figura 3 - Tarefa 2: Formas diversas com cores iguais
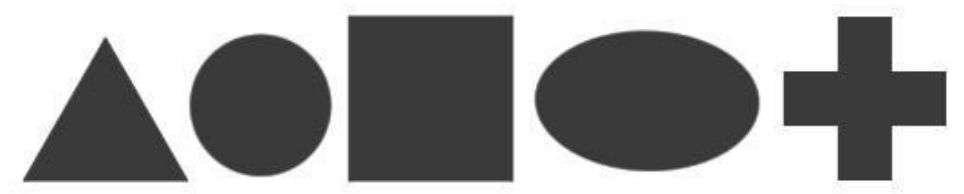

Fonte: Elaboração dos autores.

Inicialmente as respostas obtidas foram: $O$ triângulo? $O$ quadrado? A Cruz? $O$ círculo? A bola? Foi precisou explicar que pensassem um pouco antes de questionar, ou seja, que formulassem uma pergunta mais objetiva com base nas imagens. A partir dessa explicação, começaram a questionar: A figura tem quantos lados? Em que ordem ela está? Que forma tem? Neste momento, entenderam a noção do formato e características das figuras, como por exemplo, o número de arestas.

Após esse primeiro momento, as próximas tarefas introduzem os conceitos geométricos essenciais, tais como ponto, linhas, retas e segmentos. Para iniciar a tarefa 3 (Figura 4), os alunos receberam duas folhas de papel sulfite. Em uma delas deveriam dobrar ao 


\section{CRIAR EDUCAÇÃO}

Revista do Programa de Pós-Graduação em Educação - UNESC

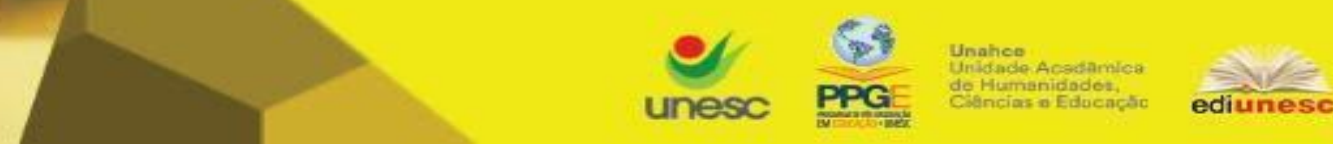

Criar Educação, criciúma, v. 10, ํo1, jan/jul 2021.- PPGE - UNESC - ISSN 2317-2452

meio e observe a figura formada, o objetivo desta tarefa é fazer com que chegassem à conclusão de que a dobra realizada configura uma linha reta. Na segunda folha, é solicitado que desenhem uma reta sem utilizar nenhum instrumento, e assim, eles percebem que, por mais que tente, sem nenhum instrumento mediador as linhas desenhadas sempre serão tortas ou curvas.

Figura 4 - Tarefa 3: Construção de retas

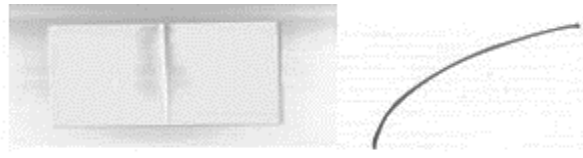

Fonte: Mame (2014, p. 73).

Segundo Mame (2014, p. 75), “a linha curva basicamente é assumida como a linha em geral. Nesse contexto conceitual, a linha reta é uma particularidade, entendida como linha com curvatura zero". Nesse sentido, é possível que o aluno entenda a reta como uma situação particular e a curva como geral, conceito que por vezes não é tão simples de compreender.

Na quarta tarefa (Figura 5), é solicitado que desenhem retas que interceptassem uma linha curva, e em seguida, apontassem os locais interceptados. Os alunos observaram diferentes pontos de encontro, concluindo que as linhas são formadas por infinitos pontos (ROSA, 2012). Assim, chegam a conclusão do conceito que uma linha é formada por infinitos pontos, sem que o professor expressasse isso como um dogma, ao qual eles devessem aceitar e decorar.

Figura 5 - Tarefa 4: Construção do conceito de reta

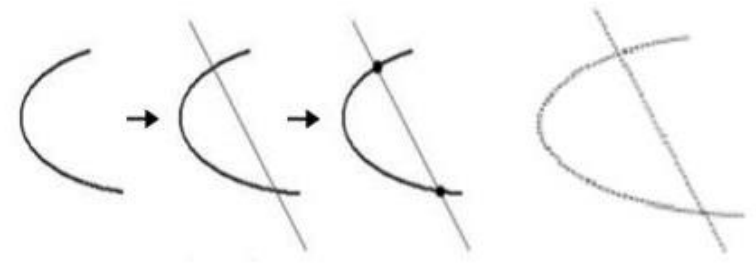

Fonte: Rosa (2012, p. 88).

Durante o desenvolvimento dessa tarefa, os alunos foram convidados a desenhar no quadro e em seus cadernos (Figura 6). Alguns observaram que foram construídas várias linhas retas, percebendo o conceito mencionado anteriormente. 


\section{CRIAR EDUCAÇÃO}

Revista do Programa de Pós-Graduação em Educação - UNESC

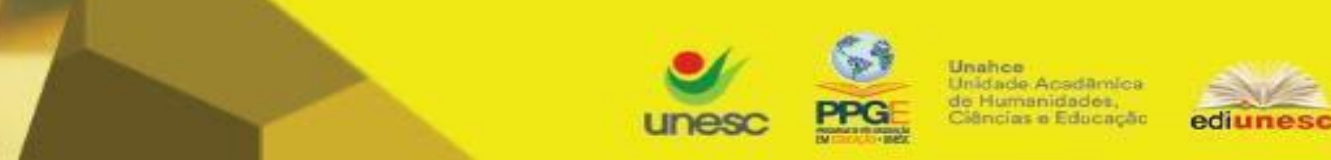

Criar Educação, criciúma, v. 10, ํo1, jan/jul 2021.- PPGE - UNESC - ISSN 2317-2452

Figura 6 - Tarefa 4: Desenvolvimento do estudante

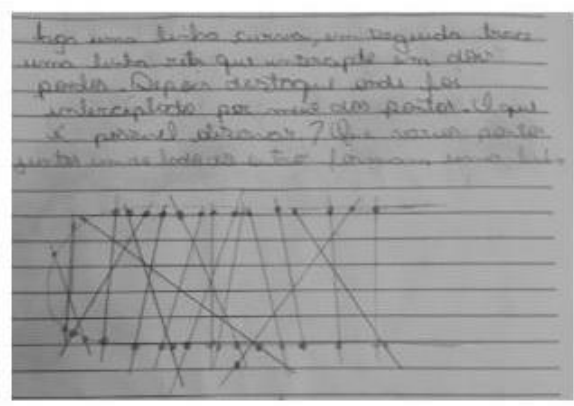

Fonte: Caderno do estudante.

$\mathrm{Na}$ tarefa 5 (Figura 7), foi solicitado que fizessem uma linha reta, marcando dois pontos sobre ela e destacando o intervalo entre eles. A distância realçada é nomeada de segmento.

Figura 7 - Tarefa 5: Segmento de reta

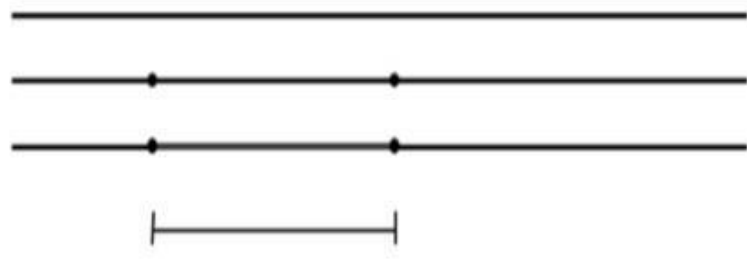

Fonte: Rosa (2012, p. 89).

Salientou-se duas propriedades em relação a definição de segmento: "é uma parte da reta e está limitado pelos dois lados. Da presença dessas duas propriedades se deduz a conexão entre a reta e o conceito de segmento de reta" (ROSA, 2012, p. 89). Assim é possível perceber o segmento de reta como um espaço delimitado de uma reta, que é infinita.

Para o desenvolvimento do pensamento do aluno, o professor propôs que fossem feitos dois pontos em uma folha, e que traçassem um segmento entre esses pontos (Tarefa 6; Figura 8). Novamente eles são questionados: "Qual tipo de linha foi desenhada? O quanto ela pode ser estendida? Ela tem fim ou não?” (ROSA, 2012, p. 89). Diante das argumentações, foi perceptível chegarem à conclusão de que é possível continuar o traço da linha, em ambos os lados. A linha reta por não possuir extremos determinados, poderá ser aumentada infinitamente. 


\section{CRIAR EDUCAÇÃO}

Revista do Programa de Pós-Graduação em Educação - UNESC

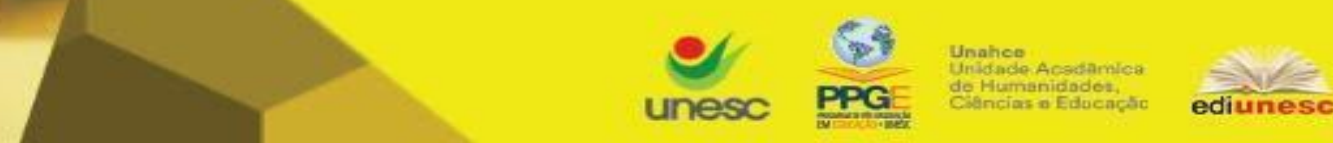

Criar Educação, Criciúma, v. 10, nº1, jan/jul 2021.- PPGE - UNESC - ISSN 2317-2452

Figura 8 - Tarefa 6: Elaboração de uma linha reta

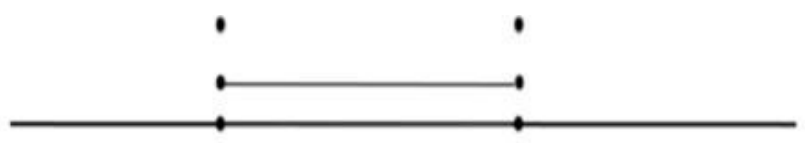

Fonte: Mame (2014, p. 77).

Para a sétima tarefa (Figura 9), foi solicitado que marcassem quatro pontos em seus cadernos de maneira que três deles não formassem uma linha reta, conforme a figura:

Figura 9 - Tarefa 7: Modelo da distribuição dos pontos no espaço

Fonte: Elaboração dos autores.

Com os pontos marcados, era preciso que ligassem os pontos, formando segmentos (Figura 10). Segundo Mame (2014, p. 86), “como consequência, surge a linha composta de segmentos, porém não é reta. Pode ser traçada com uma linha reta, entre dois pontos, porém como não estão alinhadas, elas se quebram nesses lugares". Com isso, o professor compartilha com os alunos a denominação deste tipo de linha, ou seja, "linha quebrada aberta", visto que é possível identificar pontos de início e fim.

Figura 10 - Tarefa 7: Maneira como os pontos devem serem ligados

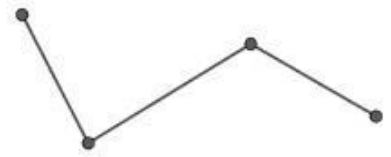

Fonte: Elaboração dos autores.

Durante a aula o professor fez as seguintes perguntas: Agora que ligamos estes segmentos, o que vocês conseguem observar? E onde está o início e o fim desta construção? Na sequência, foi respondido: Foi formado linhas que se quebram nos pontos. Você pode escolher onde é o início e o fim.

A oitava tarefa (Figura 11), teve como objetivo, desenvolver o conceito de linha fechada. Para isso, o professor solicita que os alunos copiem quatro pontos de acordo com o modelo apresentado. Diferentemente da tarefa anterior, nesta eles devem conectar os pontos, incorporando, desta vez, os pontos considerados extremos. De acordo com Mame (2014, p. 87), “deste movimento obtém-se uma linha quebrada que não tem começo e fim especificados. 


\section{CRIAR EDUCAÇÃO}

Revista do Programa de Pós-Graduação em Educação - UNESC

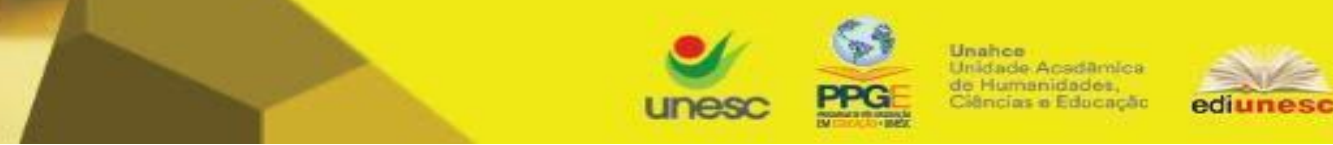

Criar Educação, criciúma, v. 10, ํo1, jan/jul 2021.- PPGE - UNESC - ISSN 2317-2452

Compete ao professor dizer que esse tipo denomina-se fechada". Este se apresenta como um conceito importante para desenvolver os estudos de polígonos.

Figura 11 - Tarefa 8: Desenvolvimento do conceito de linha quebrada fechada

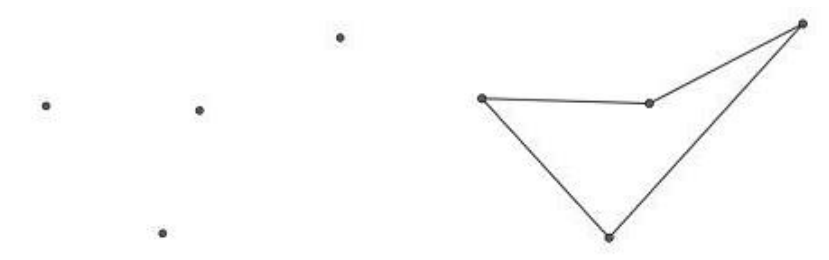

Fonte: Elaboração dos autores.

Após estudos sobre pontos, segmentos, linhas quebras abertas/fechadas, linhas curvas abertas/fechadas, foram distribuídas tarefas para que pudessem identificar por meio dos pontos, quais linhas eram possíveis ser construídas (Figura 12). Com esta atividade foi possível perceber o desenvolvimento dos alunos em relação aos conceitos estudados e identificar as principais dúvidas.

Figura 12 - Tarefa de caráter avaliativo e de controle

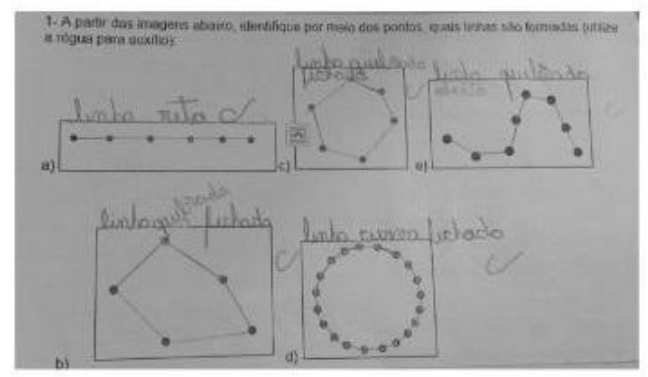

Fonte: Caderno do estudante.

Para Mame (2014, p. 87), essas tarefas “trazem um novo conteúdo pré-anunciativo para novos conceitos, quais sejam: figuras planas". A partir das figuras formadas por linhas fechadas quebradas, identifica-se diferentes figuras que são classificadas conforme o número de lados (três lados: triângulo; quatro lados: quadrilátero; cinco lados: pentágono; e assim por diante).

No livro didático (Figura 13), o autor aborda a classificação dos polígonos sem contextualizar. As informações são apresentadas de forma pronta e acabada, divergindo do estipulado pela THC. Nesta, o polígono é conceituado como uma figura formada por linhas retas quebradas e fechadas. Diante do exposto, é possível identificar como acontece a 


\section{CRIAR EDUCAÇÃO}

Revista do Programa de Pós-Graduação em Educação - UNESC

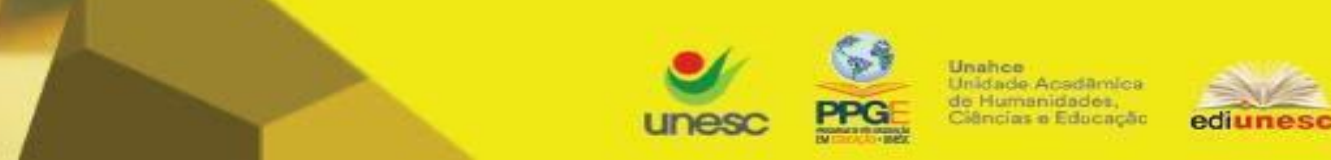

Criar Educação, criciúma, v. 10, ํo1, jan/jul 2021.- PPGE - UNESC - ISSN 2317-2452

diferenciação do ensino-aprendizagem quando é utilizado apenas o livro didático, pois, na THC o conhecimento de polígonos é desenvolvido de forma gradativa com apoio dos estudantes.

Figura 13 - Classificação de polígonos pelo livro didático

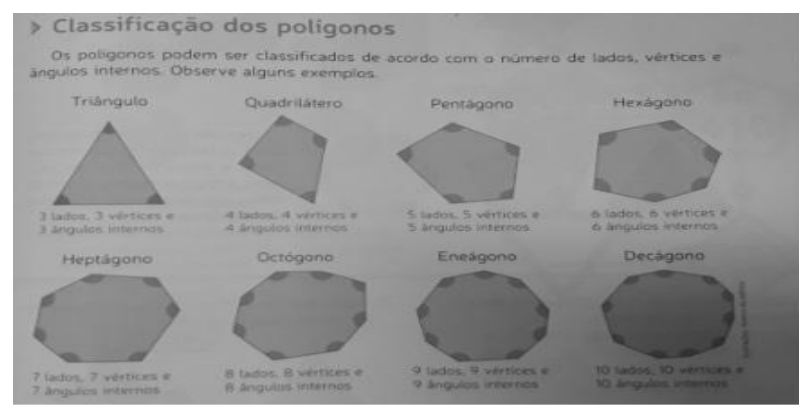

Fonte: Souza (2015, p. 179)

A tarefa 9 (Figura 14) tem como propósito definir uma linha fechada não quebrada. No lugar de desenhar quatro pontos, foi desenhado dois pontos. Os alunos deveriam ligar esses pontos utilizando de duas linhas. Segundo Mame (2014, p. 88), “o debate necessário para que se atinja a finalidade prevista para a situação apresentada é de tal modo, que leva à conclusão de que se trata de uma linha curva fechada". Assim ao perceber que as linhas não são retas, o estudante chega à conclusão que é possível formar figuras com linhas curvas também.

Figura 14 - Tarefa 9: Desenvolvimento do conceito de linha curva fechada

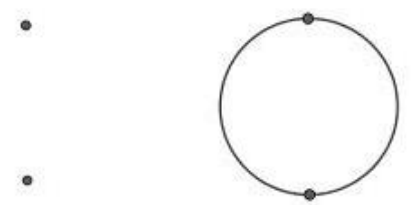

Fonte: Elaboração dos autores.

Para introduzir o conceito de ângulos (Tarefa 10; Figura 15), foi solicitado que construíssem duas retas e que estas possuíssem um ponto em comum. Ao produzir tal figura é possível observar uma divisão em quatro partes.

Figura 15 - Tarefa 10: Início do conceito de ângulo

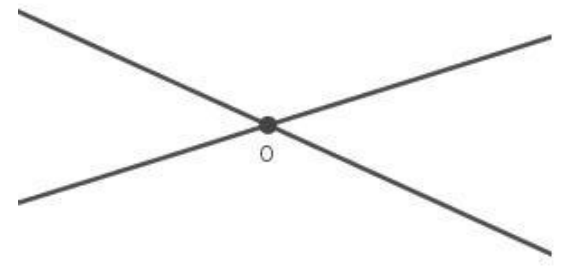

Fonte: Elaboração dos autores. 


\section{CRIAR EDUCAÇÃO}

Revista do Programa de Pós-Graduação em Educação - UNESC

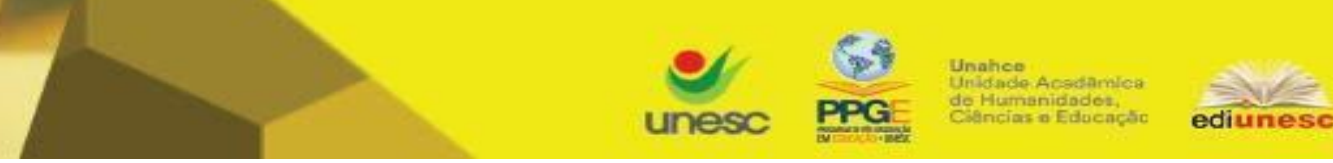

Criar Educação, Criciúma, v. 10, no1, jan/jul 2021.- PPGE - UNESC - ISSN 2317-2452

Logo após, foi sugerido colorir uma das partes da superfície, não sendo necessário fazê-la por inteiro, visto que as linhas podem continuar. A seguir, foi contornado as linhas para estabelecer um espaço entre duas retas. Para essa parte destacada, ficou denominado de ângulo, conforme a figura 16. (MAME, 2014).

Figura 16 - Desenvolvimento de ângulo pelo estudante

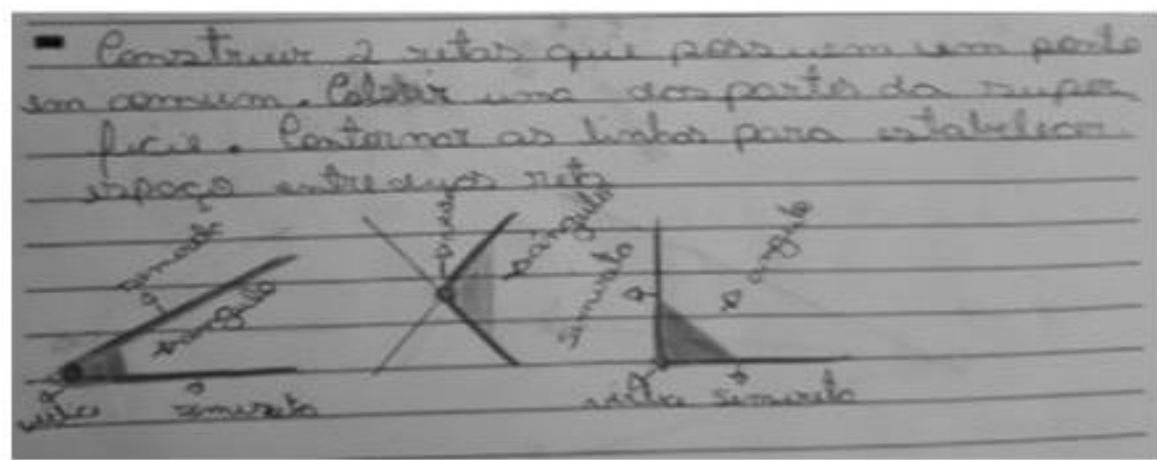

Fonte: Caderno do estudante.

Segundo Pogorélov (1974, p.22 apud MAME, 2014, p.129), o ângulo é definido como uma "figura formada por duas semirretas distintas com um ponto de origem comum. Este ponto se denomina vértice do ângulo e as semirretas recebem o nome de lados do ângulo." A elaboração deste conceito, aconteceu de maneira processual, a partir da participação dos alunos durante a construção das retas, assim, foi sendo definido o conceito principal de ângulo.

Diferentemente do sugerido pela THC, no livro didático, o conceito de ângulo é dado inicialmente de maneira empírica, mostrando visualmente aos alunos onde é possível perceber a existência de ângulo (Figura 17), sem abordar propriamente do conceito.

Figura 17 - Abordagem empírica sobre ângulos realizado pelo livro didático

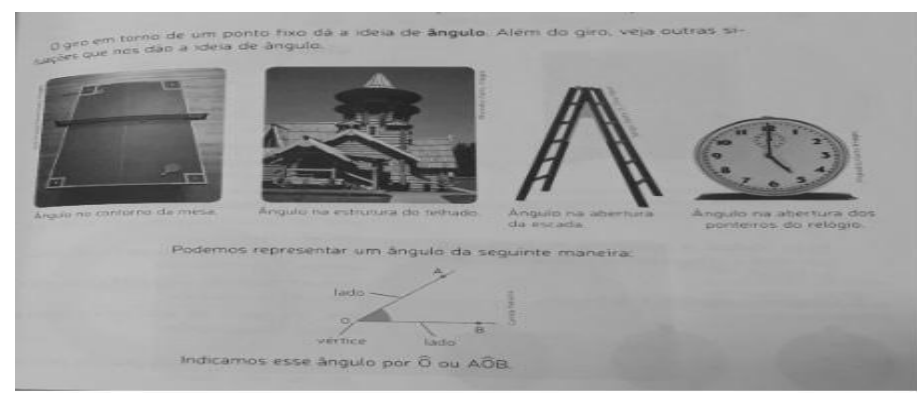

Fonte: Souza (2015, p. 161). 


\section{CRIAR EDUCAÇÃO}

Revista do Programa de Pós-Graduação em Educação - UNESC

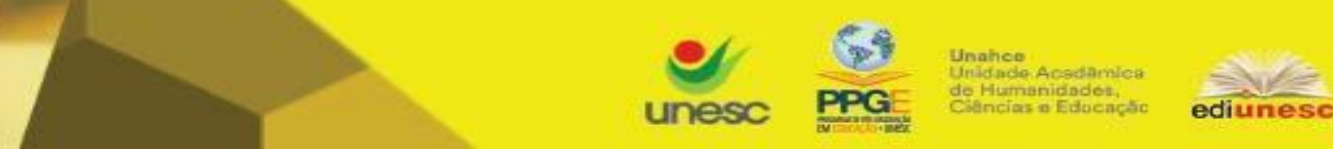

Criar Educação, Criciúma, v. 10, no1, jan/jul 2021.- PPGE - UNESC - ISSN 2317-2452

Para dar continuidade, é apresentada a figura 18. Na imagem, o ângulo é definido por três pontos: o primeiro $\mathrm{O}$, sendo o vértice; os pontos $\mathrm{A}$ e $\mathrm{B}$ e as suas retas a e b. É possível perceber a existência de um ângulo formado entre as retas.

Figura 18 - Definição da formação de ângulo

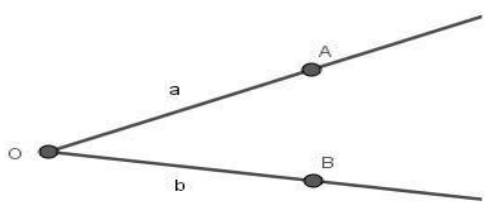

Fonte: Elaboração dos autores.

Na sequência, foi questionado como traçar ângulos retos, ou seja, que possuam $90^{\circ}$. Salientando a essência, Pogorélov (1974, p. 19 apud Mame, 2014, p. 132-133) o detalha como: "composto de duas semirretas perpendiculares que formam quatro ângulos idênticos $\alpha=90^{\circ}$; qualquer dos três ângulos restantes são seus adjacentes". Assim sendo, os ângulos retos podem ser compreendidos como uma parte resultante da divisão do ciclo trigonométrico $\left(360^{\circ}\right) \mathrm{em}$ quatro partes iguais (quadrantes).

Além dos ângulos retos, existem também outros tipos de ângulos: "agudo, se menor que um ângulo reto; obtuso, se maior que o reto $\left(90^{\circ}\right)$ e menor que raso $\left(180^{\circ}\right)$ " (MAME, 2014, p. 133) (Figura 19). Em outras palavras pode-se representar o ângulo agudo $\alpha$ tal que $\alpha<90^{\circ}$, e o ângulo $\beta$ obtuso tal que $180^{\circ}>\beta>90^{\circ}$.

Figura 19 - Estudo dos ângulos agudo e obtuso

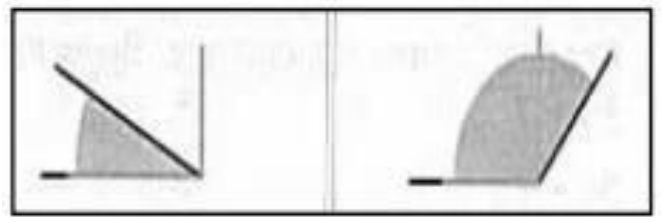

Fonte: Давыдов et al. (2012, p. 44 apud Mame, 2014, p. 133).

Na sequência, o professor entregou impresso uma tarefa, na qual os alunos deveriam identificar, em cada imagem, quais possuíam ângulos retos, agudos ou obtusos (Figura 20). Para obter os dados exatos de cada ângulo, apresenta-se o transferidor e a maneira de utilizá-lo para medir os ângulos. 


\section{CRIAR EDUCAÇÃO}

Revista do Programa de Pós-Graduação em Educação - UNESC

\section{Criar Educação, Criciúma, v. 10, nº1, jan/jul 2021.- PPGE - UNESC - ISSN 2317-2452}

Figura 20 - Tarefa de caráter avaliativo e de controle

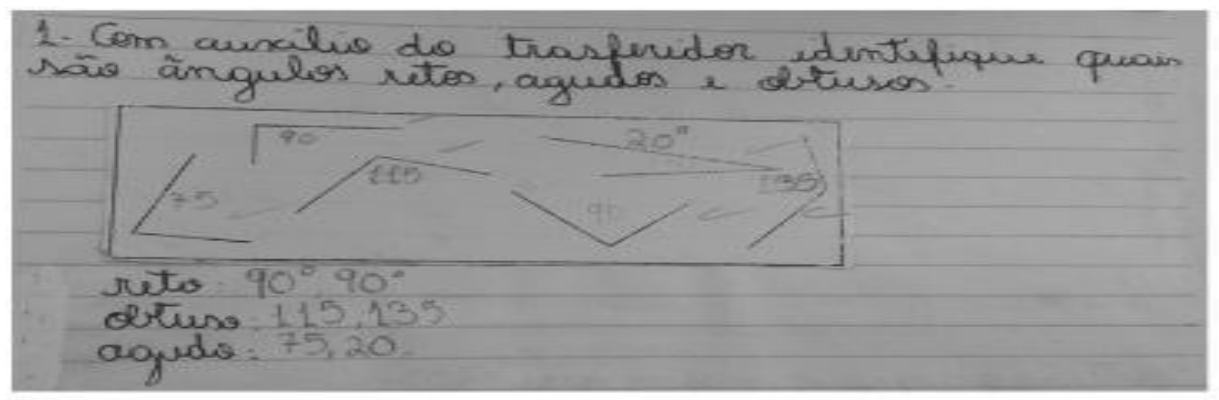

Fonte: Caderno do estudante.

Ao finalizar este estudo de identificação e classificação dos ângulos, inicia-se então, o estudo dos polígonos que conceitualmente englobam pontos, linhas, segmentos e ângulos (MAME, 2014). Diante do quadrilátero, os alunos não tiveram dificuldades para identificar, pois já haviam estudado sobre linha quebrada fechada.

O quadrilátero é uma figura geométrica constituída por quatro vértices $(A, B, C$ e D), e de segmentos $\mathrm{AB}, \mathrm{BC}, \mathrm{CD}$ e $\mathrm{AD}$ que unem esses pontos. "O polígono é convexo se a reta que contém qualquer um de seus lados encontra-se em mesmo semiplano. Os segmentos que unem os vértices A e C, B e D do quadrilátero denominam-se diagonais” (MAME, 2014, p. 137).

Um dos primeiros quadriláteros estudados no campo conceitual geométrico foi o paralelogramo, cujos lados opostos são paralelos. Para a tarefa seguinte, foi entregue impresso um quadrilátero com todos os ângulos retos. Foi solicitado que identificassem, com o uso do transferidor, quais as medidas dos seus ângulos internos. A conclusão obtida foi que todos os ângulos eram de 90 graus. Em seguida, o professor informou que a figura com essa característica (quatro lados e ângulos de 90 graus), chama-se retângulo.

Em seguida, foi abordado outro quadrilátero, o quadrado. Diante disso, foi solicitado que fizessem segmentos que possuíssem o mesmo comprimento. Segundo Mame (2014, p. 139), "o quadrado pode ser definido como um retângulo, formado por quatro pontos e quatro segmentos iguais que definem os seus lados". Assim os alunos percebem uma nova característica, além de ângulos iguais $\left(90^{\circ}\right)$ e quatro lados, no quadrado todos os lados possuem a mesma medida de comprimento.

Em seguida, a próxima tarefa (Figura 21) teve por objetivo analisar as diferentes figuras e verificar as características em relação ao quadrado. 


\section{CRIAR EDUCAÇÃO}

Revista do Programa de Pós-Graduação em Educação - UNESC

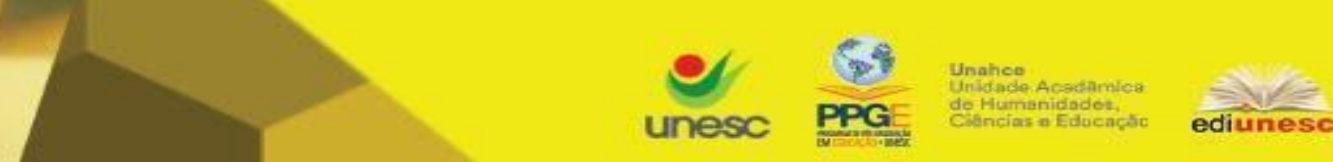

Criar Educação, criciúma, v. 10, ํo1, jan/jul 2021.- PPGE - UNESC - ISSN 2317-2452

Figura 21 - Tarefa sobre estudo do quadrilátero e suas características

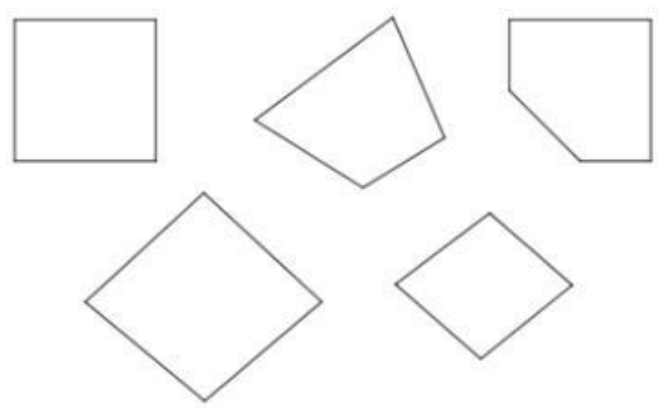

Fonte: Elaboração dos autores.

Os estudantes constataram que havia apenas um quadrado, porém, alguns afirmaram que, se fosse possível girar um dos quadriláteros, seria encontrado outro quadrado. A partir desta observação, foi explicado que havia dois losangos na figura, informando que um quadrado é também um losango, contudo, nem sempre um losango será um quadrado, pois, seus ângulos internos podem apresentar medidas diferentes. O professor salienta que o losango é um paralelogramo com todos os lados iguais (MAME, 2014). A partir disso, os alunos tiveram facilidade em identificar os diferentes quadriláteros.

Novamente, no livro didático, a classificação é dada de forma pronta, sem construir o conceito com os alunos, como é possível observar na figura 22. Essa objetividade do livro em apenas conceituar os quadriláteros sem discuti-los pode ser um fator influenciador para que os estudantes tenham dificuldade em aprender, muitas vezes, recorrendo apenas a técnicas de memorização das características do polígono.

Figura 22 - Classificação de paralelogramos feita pelo livro didático

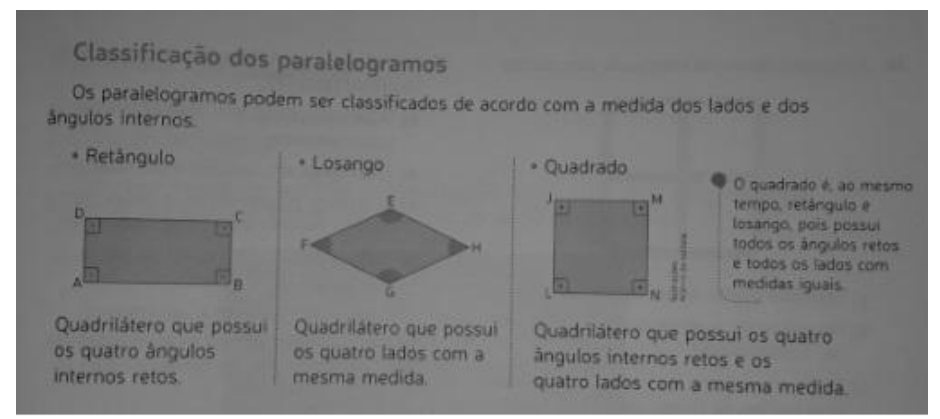

Fonte: Souza (2015, p. 187).

Após os estudos dos quadriláteros, iniciou-se o conceito dos triângulos. Com o uso dos transferidores, o professor pediu para construírem uma linha quebrada fechada de três 


\section{CRIAR EDUCAÇÃO}

Revista do Programa de Pós-Graduação em Educação - UNESC

Criar Educação, Criciúma, v. 10, nำ1, jan/jul 2021.- PPGE - UNESC - ISSN 2317-2452

segmentos com apenas um ângulo reto, conforme figura 23. Muitas dúvidas surgiram durante o desenvolvimento desta tarefa. Portanto, o docente a realizou com os alunos, primeiramente construindo uma linha reta, em seguida, marcou um ponto qualquer dessa reta. Com o uso do transferidor, foi localizado o ângulo de 90 graus e na sequência, traçou-se um segmento perpendicular. Mediante ao exposto, foi perguntado: Quantos segmentos já foram construídos? Então falta construirmos mais quantos? Os alunos responderam: Dois segmentos. Mais um.

O professor fez perguntas sobre como terminar essa tarefa, onde poderia ser construído o último segmento. Informou-se que o último segmento poderia ser feito em qualquer lugar, desde que os três segmentos estivessem ligados, pois a tarefa solicitada era a construção de uma linha quebrada fechada.

Figura 23 - Estudo do triângulo

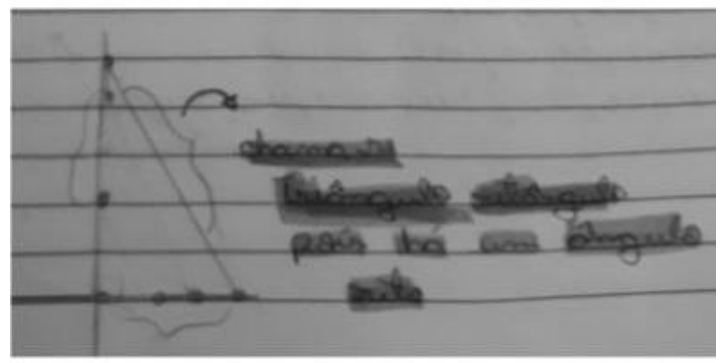

Fonte: Caderno do estudante.

Em seguida, foi proposto a construção de outra linha quebrada fechada de três segmentos, contudo, com dois ângulos retos (MAME, 2014). Diante da situação apresentada, os alunos perceberam que não seria possível construir um triângulo com dois ângulos retos. Consegue-se construir apenas o triângulo com um ângulo reto, nomeado de triângulo retângulo. Assim, foi conceituado que "chama-se triângulo retângulo aquele que tem um ângulo reto", portanto, os outros ângulos são agudos (POGORÉLOV, 1974, p. 63 apud MAME, 2014, p. 140).

O triângulo retângulo, diferente dos demais, possui características específicas: “o lado oposto ao ângulo reto se chama hipotenusa e os outros dois lados se chamam catetos. Os ângulos opostos aos catetos são agudos" (POGORÉLOV, 1974, p. 63 apud MAME, 2014, p. 140). Na continuidade, foi proposto que os estudantes construíssem dois triângulos (Figura 24). O primeiro com ângulos agudos, já o segundo, deveria possuir um de seus ângulos obtuso. Após 


\section{CRIAR EDUCAÇÃO}

Revista do Programa de Pós-Graduação em Educação - UNESC

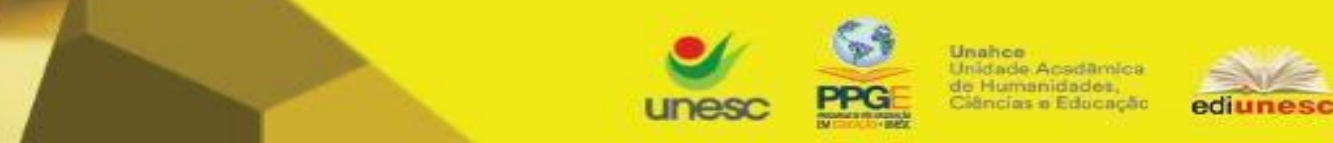

Criar Educação, criciúma, v. 10, ํo1, jan/jul 2021.- PPGE - UNESC - ISSN 2317-2452

o desenvolvimento, foi apresentado o triângulo obtuso ou obtusângulo, quando este apresenta um ângulo obtuso. O outro triângulo é agudo ou acutângulo, pois todos seus ângulos são agudos.

Figura 24 - Estudo dos triângulos obtuso e agudo

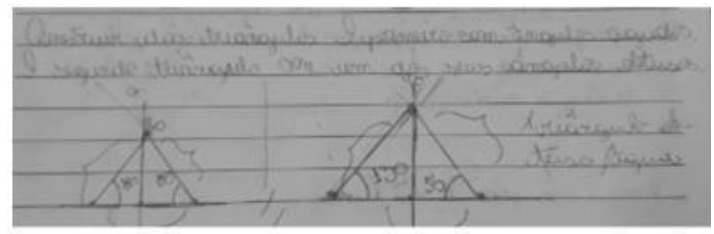

Fonte: Caderno do estudante.

Para desenvolver o conceito de triângulo isósceles, foi solicitado que desenhassem um triângulo obtuso e um triângulo agudo, ambos com dois ângulos iguais. Após os alunos desenvolverem a tarefa, pediu-se para analisarem algumas características desses triângulos. Foram questionados: Vocês fizeram dois ângulos iguais em cada triângulo, o que aconteceu com o comprimento dos seus lados? Após analisarem, alguns responderam: Possuem duas medidas de comprimentos iguais. Posteriormente, foi informado que esses triângulos são denominados de triângulo isósceles.

Com o objetivo de investigar o conceito de triângulo equilátero, pediu-se que construíssem, no caderno, um polígono formado por 3 segmentos com medidas dos ângulos internos iguais (Figura 25). Em seguida, solicitou-se que eles investigassem as características desse triângulo. Ao analisarem, concluíram que as medidas de comprimentos dos lados deste triângulo são iguais e os ângulos são iguais, característica essas que o professor define pertencentes ao equilátero.

Figura 25 - Conceituando triângulo equilátero

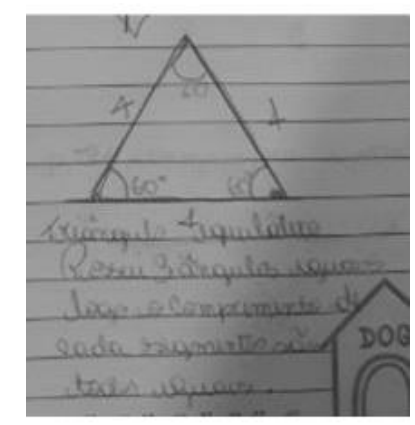

Fonte: Caderno do estudante.

A tarefa a seguir se apresenta como caráter avaliativo e de controle, que auxiliará na objetivação e identificação de figuras que apresentam características já estudadas. Esperava-se 


\section{CRIAR EDUCAÇÃO}

Revista do Programa de Pós-Graduação em Educação - UNESC

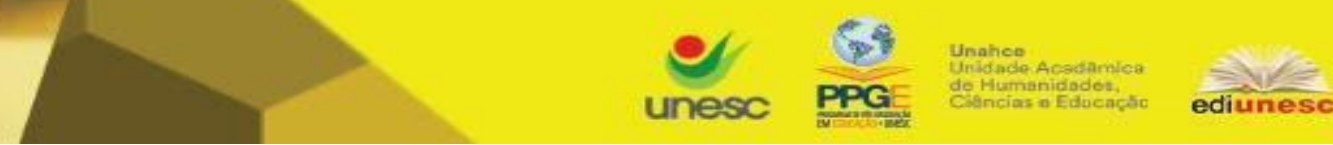

Criar Educação, criciúma, v. 10, ํo1, jan/jul 2021.- PPGE - UNESC - ISSN 2317-2452

que os alunos compreendessem e adquirissem o conhecimento da nomenclatura decorrente das especificidades de cada triângulo em relação à tipologia do ângulo e dos lados (MAME, 2014). Diante disso, foi entregue impresso figuras em que eles teriam que utilizar os transferidores para analisá-las e nomeá-las em triângulo retângulo, isósceles ou equilátero (Figura 26).

Figura 26 - Estudo das características dos triângulos

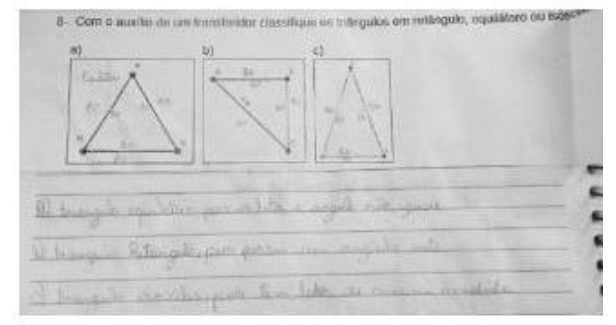

Fonte: Caderno do estudante.

As tarefas subsequentes abordam o conceito de circunferência. Primeiramente o docente pediu para marcarem em uma folha de papel um ponto K. Logo em seguida, solicitouse que construíssem um segmento $\mathrm{AB}$ qualquer. Na mesma folha, foi marcado pontos que estão a uma distância igual ao segmento $\mathrm{AB}$ em relação ao ponto K (Figura 27). Pergunta-se: Qual é a figura geométrica obtida? Questão esta que se obteve como resposta: uma circunferência.

Figura 27 - Estudo do conceito de circunferência

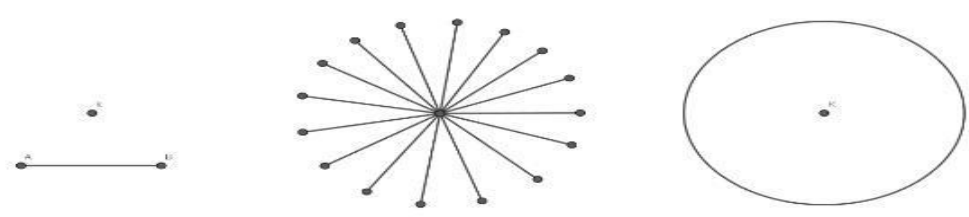

Fonte: Elaboração dos autores.

Em seguida, os alunos foram instigados a construir um segmento de maneira que uma das suas extremidades seja o centro da circunferência e a outra, qualquer ponto da circunferência. Eles discutiram as possíveis quantidades de segmentos a serem construídos e seus respectivos comprimentos. Diante disso, foram informados que este segmento se chama raio.

$\mathrm{Na}$ continuidade, elaborou-se um segmento, com extremidades em pontos quaisquer da circunferência, conforme figura 28. Segundo ГОРБОВ (2016, p. 26), “estes segmentos se chamam cordas". Por fim, questionou-se a quantidade possível de cordas a serem construídas e de que modo pode ser elaborada uma corda com o maior comprimento possível. Os alunos 


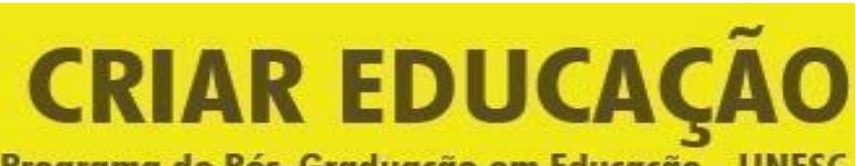

Revista do Programa de Pós-Graduação em Educação - UNESC

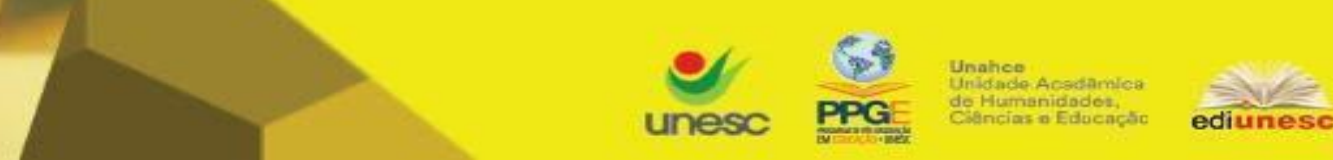

Criar Educação, criciúma, v. 10, ํo1, jan/jul 2021.- PPGE - UNESC - ISSN 2317-2452

chegaram à conclusão de que a maior deverá passar pelo centro, logo foi explicado que a corda maior se chama diâmetro.

O professor fez o seguinte questionamento: em quantas medidas uma circunferência é fracionada por um par de pontos? Ao constatar que se obtém infinitas medidas, lhes informou que essa distância entre dois pontos de uma circunferência é chamada de arco.

Figura 28 - Estudo das características da circunferência

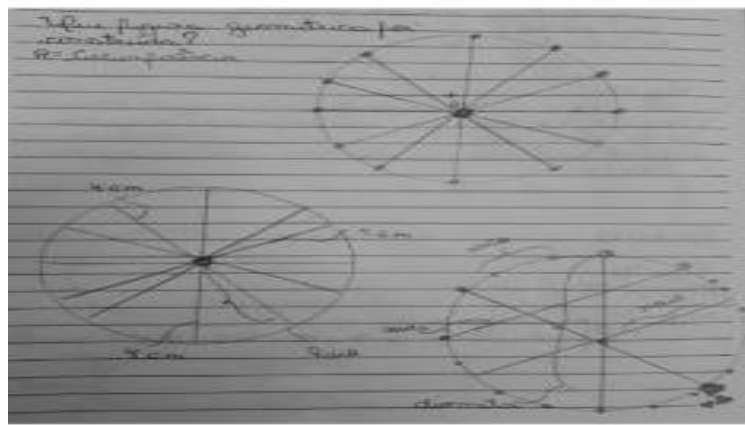

Fonte: Caderno do estudante.

Outra vez, o autor do livro didático (Figura 29) não compactua com a metodologia da THC, pois apresenta os elementos da circunferência sem incitar os alunos à construção do conhecimento, ou seja, os alunos devem ser passivos, aceitando o conceito como algo pronto e finalizado, não existe o cuidado de abordar as nomenclaturas de maneira que os estudantes consigam aos poucos compreender cada elemento.

Figura 29 - Abordagem do livro didático sobre circunferência

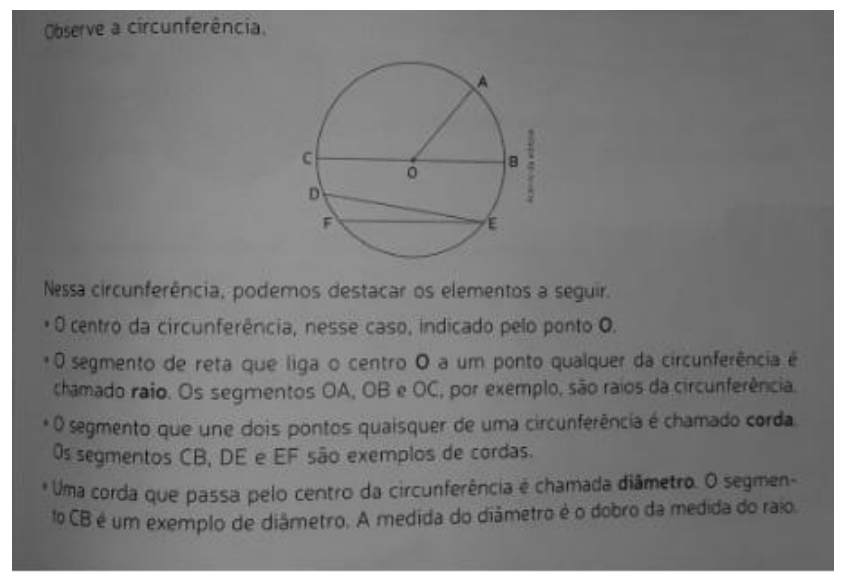

Fonte: Souza (2015, p. 189).

Diante do exposto, percebe-se que as relações geométricas de ponto, linhas (abertas, fechadas e curvas), segmentos, bem como as relações de ângulos, quadriláteros (paralelogramo, 
retângulos, quadrados e losango), triângulos e circunferência são requisitos imprescindíveis para o desenvolvimento de conceitos da geometria (MAME, 2014). E além de abordar tais conceitos, salienta-se a importância de fazê-la de maneira que o aluno realmente se aproprie e desenvolva seu conhecimento de maneira ativa.

Na sequência será abordado como sucederam os processos avaliativos das turmas, pois a THC tem a avaliação como quesito importante para a estrutura de ensino-aprendizagem. Moraes e Moura (2009, p. 105) salientam que "o significado da avaliação na atividade de ensino e de aprendizagem deve ser o de orientação e de direcionamento do processo de apropriação dos conhecimentos". Assumindo o papel de mediador, "o professor deve trabalhar com o aluno, explicar, questionar, corrigir e fazer com que a criança explique seu próprio pensamento" (NOGUEIRA, 2007, p. 87). A partir dos resultados, é possível localizar falhas no processo de ensino-aprendizagem, também, relacionadas como um indicador de excelência do aluno e da instituição.

O conhecimento prévio do aluno é utilizado como base para alcançar a compreensão de conceitos mais complexos, "o que determina a aprendizagem dos sujeitos é o grau de domínio da essência do conceito e sua atividade efetiva com os conhecimentos apropriados" (MORAES E MOURA, 2009, p. 113). Os autores agregam que o professor pode avaliar de diversas maneiras. Cada conteúdo tem um instrumento que identifica o grau de percepção do aluno em relação aos conceitos que ele consegue realizar e aqueles em que encontra dificuldades.

No processo avaliativo, foram elaboradas três avaliações: a primeira individual e com consulta, a segunda em dupla e sem consulta, e a terceira individual. Esse método avaliativo foi desenvolvido com base no regulamento das escolas, que solicitaram no mínimo três avaliações. Na primeira avaliação, buscou-se observar as dificuldades dos alunos em relação aos conceitos de pontos, linhas, retas e segmentos. Foram realizadas quatro questões abertas, sendo que três delas o aluno deveria desenhar, mostrando seu entendimento a respeito de linhas retas e curvas, linhas quebradas abertas ou quebradas fechadas e a quarta conceituar a formação de linhas. Houve ainda duas questões fechadas, em que era preciso observar as alternativas e assinalar a opção correspondente ao que é solicitado, a primeira em relação a segmento e a segunda a respeito de linha quebrada fechada. 
Na segunda avaliação, com intuito de verificar a apropriação do conhecimento sobre ângulos e polígonos, foram elaboradas quatro questões abertas e duas questões fechadas. As questões abertas eram referentes à quantidade e classificação de ângulos, diferentes características do triângulo equilátero e isósceles, particularidades do quadrilátero quadrado. As questões fechadas abordaram sobre pontos pertencentes ao ângulo, ao polígono e a classificação de triângulos de acordo com seus ângulos.

$\mathrm{Na}$ terceira avaliação, reuniram-se os conteúdos das avaliações anteriores com o conteúdo de circunferência. Foram desenvolvidas dez questões, sendo sete abertas e três fechadas. O objetivo desta avaliação era analisar a percepção dos alunos quanto à inter-relação dos conteúdos. Nas últimas aulas, foi possível perceber que alguns estudantes já estavam mais independentes, buscando resolver as tarefas sem a orientação do professor. Segundo Peres e Freitas (2014), inicialmente os alunos não conseguem realizar o que é proposto pelo professor, contudo, o processo de independência acontece de modo gradativo, adquirindo autonomia na execução das tarefas. Assim, esta independência que aos poucos foi conquistada pelos alunos é um elemento de suma importância para perceber que a presente proposta alcançou seu objetivo primário, o de proporcionar ao estudante que de maneira ativa e crítica se aproprie e construa o seu conhecimento acerca dos conteúdos estudados.

\section{CONSIDERAÇÕES FINAIS}

Ao realizar esta pesquisa, estudaram-se, com maior profundidade, os conceitos geométricos de polígonos e formas circulares na perspectiva Histórico-Cultural. Observou-se que embora a Proposta Curricular de Santa Catarina e de Criciúma utilizem a THC como fundamento, nos livros didáticos, não existe esse compromisso em segui-la, pois apresenta os conteúdos e conceitos de forma isolada. No entanto, de acordo com a THC, o ensino de matemática deve inter-relacionar as ideias geométricas, algébricas e aritméticas.

Durante o processo de apropriação dos conceitos sobre geometria com os alunos do sexto ano, elaboraram-se tarefas com movimento de ida e volta, pois cada conceito está sempre relacionado a outro, pois o conhecimento acontece por meio das inter-relações algébricas, aritmética e geométrica. Durante o processo de ensino aprendizagem, mencionava-se o que já havia estudado para então dar continuidade a novos conceitos. 


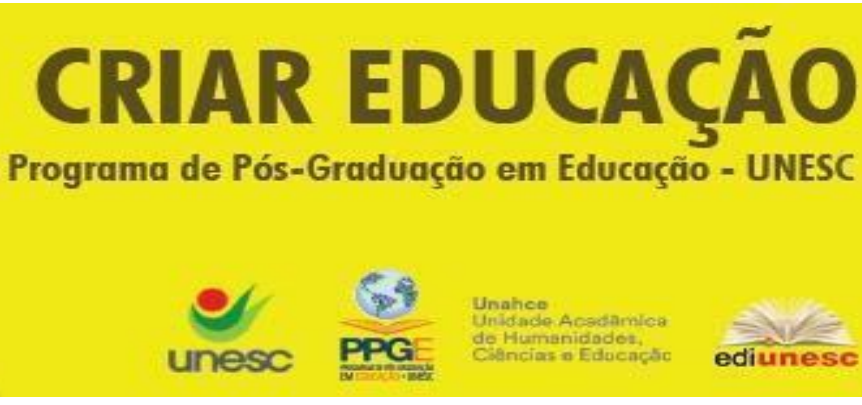

Criar Educação, Criciúma, v. 10, no1, jan/jul 2021.- PPGE - UNESC - ISSN 2317-2452

Ficou evidente a necessidade em formar o conhecimento teórico nos alunos, pois eles possuíam uma bagagem empírica, mostrando dificuldades em desenvolver algumas tarefas, precisando da orientação dos professores. Quando questionados pelos professores, se mostravam inseguros para responder, até mesmo para participar em tarefas realizadas no quadro. Foi preciso de algumas aulas para eles se sentirem motivados a perguntar, saírem de uma postura passiva, tornando-se seres ativos em caráter investigativo. Contudo, não é possível afirmar que aconteceu com todos, pois cada um tem seu ritmo de aprendizagem, mas os alunos eram instigados à busca de novos conhecimentos, procurando desenvolver o seu pensamento teórico.

Contudo, para que isso ocorra, o processo é mediado pelo professor que deve incentivar o aluno a desenvolver o seu raciocínio teórico e que desde o início da sua educação escolar seja encorajado a buscar por conceitos próprios. Entretanto, para um bom desempenho escolar, faz necessário que o professor tenha uma significativa base teórica, além da didática. Estar em sala de aula proporcionou uma breve vivência da realidade dos professores, o que possibilitou perceber que o papel do professor é de suma importância e requer muita dedicação, pois é um ambiente complexo em que muitas vezes os alunos não possuem compromisso com o que é proposto.

Por fim, ficou evidente a necessidade de trabalhar a THC desde o início da vida escolar dos alunos, pois, assim, contribuirá para que os mesmos encontrem seu próprio caminho para a formação científica e também, outras maneiras de formação. Desse modo, eles se tornarão seres de práxis (ação-reflexão-ação) e desenvolverão novos conhecimentos. Este trabalho apresentou, portanto, uma proposição de ensino que poderá servir de fundamento aos professores, seguindo a abordagem referida.

\section{REFERÊNCIAS}

DAMAZIO, A.; ROSA, J. E.; EUZÉBIO, J. da S. O ensino do conceito de número em diferentes perspectivas. In: Educ. Matem. Pesq., São Paulo, v.14, n.1, p.209-231, 2012.

DAVÍDOV, V.V. La enseñanza escolar y el desarrollo psíquico: investigación psicológica teórica y experimental. Moscú: Editorial Progresso, 1988. 


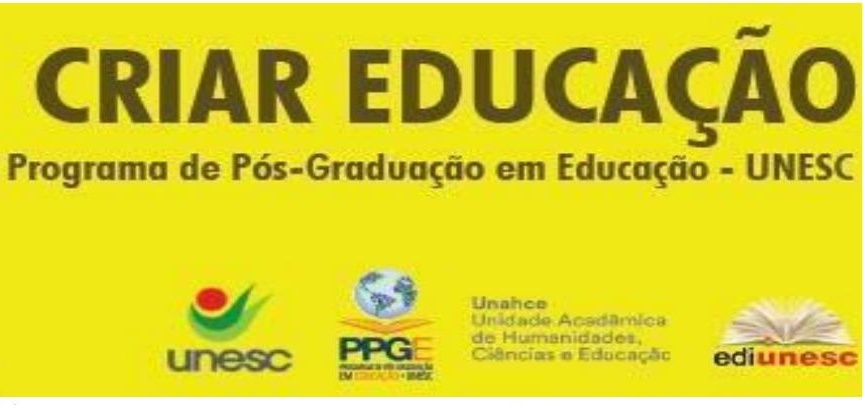

Criar Educação, Criciúma, v. 10, no1, jan/jul 2021.- PPGE - UNESC - ISSN 2317-2452

DAVÝDOV, V. V. La renovación de la educación y el desarrollo mental de los alumnos.

Revista de Pedagogia, Santiago, n. 403, jun. 1998.

FREIRE, P. Pedagogia da autonomia: saberes necessários à prática educativa. São Paulo: Paz e Terra, 2011.

LIBÂNEO, J. C. A didática e a aprendizagem do pensar e do aprender: a Teoria Históricocultural da Atividade e a contribuição de Vasili Davydov. Rev. Bras. Educ., Rio de Janeiro, n.1, 2004. Disponível em: <http://www.scielo.br/pdf/rbedu/n27/n27a01.pdf >. Acesso em: 10 fevereiro 2019.

MAME, O. A. C. Os conceitos geométricos nos dois anos iniciais do ensino fundamental na proposição de davýdov. Dissertação (Mestrado em Educação) - Programa de Pós-

Graduação em Educação, Universidade do Extremo Sul Catarinense, Santa Catarina, 2014.

MORAES, S. P. G.; MOURA, M. O. Avaliação do Processo de Ensino e Aprendizagem em Matemática: contribuições da teoria histórico-cultural. Bolema, Rio Claro (SP), v. 22, n. 33, 2009. Disponível em:

<http://www.periodicos.rc.biblioteca.unesp.br/index.php/bolema/article/view/2960/2441>. Acesso em: 15 fevereiro 2019.

MORETTI, V. D. O problema lógico-histórico: aprendizagem conceitual e formação de professores de matemática. Poiésis, Tubarão, v. 8, 2014. Disponível em:

<http://www.portaldeperiodicos.unisul.br/index.php/Poiesis/article/view/1741/1420>. Acesso em: 15 fevereiro 2019.

NOGUEIRA, C. M. I. As teorias de aprendizagem e suas implicações no ensino de matemática. Acta Scientiarum. Human and Social Sciences, Maringá, v. 29, n. 1, 2007. Disponível em: <https://www.redalyc.org/html/3073/307324783012/>. Acesso em: 21 fevereiro 2019.

PERES, T. de C.; FREITAS, R. A. M. da M. Ensino desenvolvimental: uma alternativa para a educação matemática. Poiésis, Tubarão, v. 8, 2014. Disponível em:

<http://www.portaldeperiodicos.unisul.br/index.php/Poiesis/article/view/1741/1420>. Acesso em: 15 fevereiro 2019.

ROSA, J. E. da. Proposições de davydov para o ensino de matemática no primeiro ano escolar: Inter-relações dos sistemas de significações numéricas. Tese (Doutorado em Educação) - Setor de Ciências Humanas, Curso de doutorado em Educação Universidade Federal do Paraná, Paraná, 2012.

SAVIANI, Dermeval. Pedagogia Histórico-Crítica: primeiras aproximações. 10 ed. Campinas-SP: Autores Associados, 2008.

SFORNI, M. S. de F. O que a organização do ensino de conceitos revela sobre a qualidade da aprendizagem. I Encontro Paranaense de Psicopedagogia, ABPppr, 2003. 
SOUZA, J. R. de. Vontade de saber matemática, $6^{\circ}$ ano. São Paulo: FTD, 2015.

ZANELLA, A. V. Zona de desenvolvimento proximal: análise teórica de um conceito em algumas situações variadas. Temas Psicol., v. 2, n. 2, 1994. Disponível em:

<http://pepsic.bvsalud.org/scielo.php?script=sci_arttext\&pid=S1413389X1994000200011\&lng=pt\&nrm=iso>. Acesso em: 22 fevereiro 2019.

ГОРБОВ, С. Ф. et al. Математнка. Учебное пособне для 6 класса. Москва: Авторский Клуб, 2016.Tradução realizada por Elvira Kim.

Recebido outubro de 2020

Aprovado março de 2021 